\title{
Integration of the Indian Stock Market : at the angle of Time-Frequency
}

\author{
Aasif Shah \\ Pondicherry University, Puducherry, India \\ Malabika Deo \\ Pondicherry University, Puducherry, India
}

\begin{abstract}
This paper uses wavelet correlation and cross correlation techniques to examine the integration between Indian and Asia Pacific equity markets. In the sense that both time and frequency domains can be taken into consideration, wavelets have been emerged as a perfect trade-off. Our results show that the Indian market is correlated with Asia Pacific markets largely on lower frequencies or longer time horizons implying that diversification opportunities for investors are more likely to exist at higher frequencies or shorter time horizons. The cross correlation result also reveals lead-lag relationship on lower frequencies which suggests investment strategies for investors operating in Indian market facing sudden changes in Asia Pacific markets.
\end{abstract}

JEL Classifications: F36, G11, G15

Keywords: Asia Pacific, Wavelet Correlation, Wavelet Cross Correlation

\footnotetext{
* Corresponding Author: Aasif Shah; Pondicherry University, R.V.Nagar, Kalapet, 605014 Puducherry, India; Tel: +91 8903520012, E-mail: aasif127@gmail.com.

Co-author: Malabika Deo; Pondicherry University, R.V.Nagar, Kalapet, 605014 Puducherry, India; Tel: +91 9442140745, E-mail: deo_malabika@yahoo.co.in.
} 


\section{Introduction}

The Indian stock market is considered to be one of the earliest in Asia and has been in operation since 1875 . However it remained largely outside the global integration process until financial reforms initiated in 1991. During the last two decades, there has been a significant increase in its cross-border capital and financial flows and as a result, India is currently witnessing an unprecedented level of economic interdependence with both developed and developing nations. The interdependence and integration of its market is clearly reflected in its rising volatility from spill-over turmoil emerging from international markets. For example, in September 2008, national stock markets around the world declined sharply in the wake of the Lehman Brothers collapse. The Indian stock market crashed from a high of 20,000 to a low of around 8,000 points during the year 2008 2009 (Parul and Gupta 2010). It is therefore important for various stakeholders, especially international equity-market investors, to understand the relationships that exist between certain economies in order to benefit from effective diversification strategies by adjusting their portfolios accordingly. The study of economic and market interdependence holds important implications for the theory of financial economics which posits that portfolio risk can be reduced through international portfolio diversification. A major argument regarding stock market interdependence was laid by Stulz (1999), who asserted that increased market integration leads to international risk sharing resulting in lower cost of equity capital. Since the first empirical work on the advantages of internationally well-diversified portfolios (Grubel 1968), there has been a substantial debate in international finance on the linkages between stock markets and their effects on diversification (Levy and Sarnat 1970, Shiller 1989, Kasa 1992, Richards 1995, Forbes and Rigobon 2002, Brooks and Del Negro 2004, Syriopoulos 2007). Initially the investigations on stock market linkages were pursued through simple correlation (Granger and Morgenstern 1970, Brooks and Del Negro 2004, Mukherjee 2007). Of late more advanced tools like rolling window correlation (Brooks and Del Negro 2004), switching regimes (Hassler 1995), and cointegration methods (Voronkova 2004) have also been used. Other studies (Chung and Liu 1994, Islam 2014) incorporated vector auto-regression, a vector error correction model, impulse response analysis, forecast error variance decomposition, and granger causality techniques. Recently International Capital Asset Pricing Model (ICAPM) was also used to study the dynamics of market integration (Khaled G. et al. 2013). The idea was to bring to bear different 
kinds of tools so as to capture an unambiguous linkage between the underlying markets. However, the methodological experimentations led the authors to two different schools of thoughts. Some propounded that there is essentially a long run relationship, while others argued that the relationship is exclusively short-term. But the fact remains that the authors have overlooked the fact that the problems hinged on co-integration, error correction techniques, and the like. For instance, these models have been constructed to deal with not more than two time frequencies.

In the Indian context, several studies have been carried out to investigate stock market linkages with both developed as well as developing markets. By using the cointegration and Granger-causality tests, the study by Bose and Mukherjee (2006) inferred that the Indian market offers only a short term scope for reaping benefits of portfolio diversification. Moreover, they reported weak correlations with United States (US) and Japanese returns. Their findings however contradict those of a study by Raj and Dhal (2008) that employed multivariate co-integration analysis, and concluded that India's dependence on global markets like those of the US and United Kingdom (UK) was considerably higher relative to regional markets like Singapore and Hong Kong. He further argued that the Indian market would be influenced by the diversification objective of foreign investors only in the short run. Additionally Tripathi and Sethi (2010) showed that the Indian market is integrated with the US stock market but not with Japan, the UK, or China and suggested that long term benefits can be derived from portfolio diversification.

Market participants operate on different time scales depending upon their requirements and thus the true dynamic structure of the relationship between variables might vary over different time scales. Viewing this phenomenon from a portfolio diversification perspective, this means that market participants with short-term investment horizons are active at higher frequencies while those with longer-term investment horizons operate on longer scales. Therefore it is imperative to gauge comovements in stock markets on multiple scales. Wavelet techniques naturally provide a multi-scale analysis of data. This new approach is able to characterize the multiscale aspects of a return time series to serve as a protocol for various traders, who view the market with different time horizons. In India, using wavelets to examine the beta for Indian stocks Deo and Shah (2012a, 2012b) argue that beta has a tendency to vary depending on the time horizon of investors. Given these diverse horizons, wavelets can provide an easy vehicle to study the multi-scale properties of financial return series with. With regard to co-moments of return series several studies (Lee 2004, Fernandez 2005, 
Rua and Nunes 2009, Raghavan et al. 2010) examined wavelet correlation and concluded that benefits of diversification could be exploited at higher frequency intervals. In this paper, we examine to what extent Asia Pacific equity markets are integrated over multiple scales with the Indian equity market. The findings suggest that the integration of the Indian market with Asia Pacific markets increases monotonically with increase in the wavelet scale. This in turn implies time varying diversification opportunities for Indian investors. It was also observed that there exists a lead-lag relationship between India and sample markets during longer time horizons which means that a price change in Asia Pacific markets can drive or pull the Indian market during such time periods. Thus, investors, fund managers, and regulators can use our insights to formulate effective portfolio diversification strategies.

The remainder of the paper is organised as follows. Section II describes the Wavelet Multi-scale decomposition. Section III illustrates the wavelet correlation. Section IV discusses wavelet cross covariance and correlation. Section V gives a framework of the data description and discussion of results and finally Section VI draws conclusions and policy implications.

\section{Wavelet Multi-Scale Decomposition}

The classic time domain approach aims at studying the underlying properties of an economic variable whose realizations are recorded at a predetermined frequency. This approach does not convey any information regarding the frequency components of a variable. Thus it makes the pretended assumption that the relevant frequency to study the behaviour of the variable matches its sampling frequency. However, an issue arises if the variable realizations depend in a complicated manner on several frequency components. Wavelet techniques possess an inherent ability to decompose a time series into several sub-series which may be associated with a particular time scale. In particular, wavelet methods present a lens to the researcher, which can be used to zoom in on details and draw an overall picture of a time series at the same time. Until recent years stock market integration has been mostly analyzed following the conventional time-domain 
approach where the frequency domain ${ }^{1}$ had been ignored. There is a possibility that the relationship would differ at different frequencies due to the heterogeneous trading nature of market participants. The dynamic linkage between stock markets can therefore vary across frequencies and such relationship may even change over time. Given its ability mentioned above, the wavelet approach is pertinent. To be precise, wavelet methods deconstruct return series into different time-frequency scales. The deconstruction and localization property makes wavelets useful because it allows for handling a nonstationary time series that may change quickly over time (Deo and Shah 2012a).

\section{A. The maximal overlap discrete wavelet transform}

A time series can be decomposed or deconstructed into a number of levels. For a complete deconstruction of a return series of length $N=2^{j}$ using the Discrete Wavelet Transform (DWT), the maximum number of levels in the decomposition is $J$. Although extremely popular due to its intuitive approach, the DWT suffers from two major drawbacks: dyadic length requirements for the series to be transformed and the fact that DWT is a non-shift variant which means that if data points from the beginning of the series are put aside, the lower frequencies will yield different crystals with completely different values. In order to address these two drawbacks, we relied on the Maximal Overlap Discrete Wavelet Transform (MODWT) because of important reasons as mentioned by Percival and Walden (2000). They are (i) MODWT of level $J$ being well-defined by any sample size $N$ and the MODWT wavelet variance estimator is asymptotically more efficient than the same estimator based on DWT. This is because the MODWT transform loses orthogonality but acquires attributes suitable for economic research. (ii) The MODWT is invariant to circularly shifting the original time series. (iii) The details and smooth coefficients of MODWT multi-resolution analysis are associated with zero phase filters. (iv) Moreover the MODWT is a non-decimated form of the DWT having many advantages over the DWT including the ability to handle arbitrary length sequences and shift invariance. While the DWT function can handle arbitrary length sequences, it does so by means of an ad hoc storage system for odd length scaling coefficient crystals. The MODWT needs no such scheme and is more robust in this

\footnotetext{
Frequency is the rate of change with respect to time. Change in a short span of time means high frequency. Change over a long span of time means low frequency. If a signal does not change at all, its frequency is zero. If a signal changes instantaneously, its frequency is infinite.
} 
respect. The cost of the MODWT is in its redundancy. For an $N$ point input sequence, there are $N$ wavelet coefficients per scale. However, the number of multiplication operations is $\mathrm{O}(N \log 2(N))$ which is the same as the fast Fourier transform, and is acceptably fast for most situations. With this estimator, the wavelet and scaling coefficients at the first level of decomposition are obtained by convolution of the data series with the father wavelets $\psi(t)$ and mother wavelet $\psi(t)$

$$
\int \psi(t) d t=0, \quad \int \varphi(t) d t=1
$$

The father wavelets are used for the low frequency smooth components parts of a signal and the mother wavelets are used for the high-frequency details components. That is, father wavelets are used for the trend components and mother wavelets are used for all the deviations from trend. Hence, a sequence of mother wavelets is used to represent a function and only one father wavelet is used to represents a function. To continue the frequency-by-frequency decomposition of the original signal, one typically resorts to what is known as the pyramid algorithm shown in Figure 1. In short, wavelet literature has emerged with a number of wavelets families.

However, in the empirical literature the majority of the literature is concentrated on the use of orthogonal wavelets such as the Haar, Daublets, Symmlets, and coiflets.

\section{Figure 1. Flowchart of the pyramid algorithm}

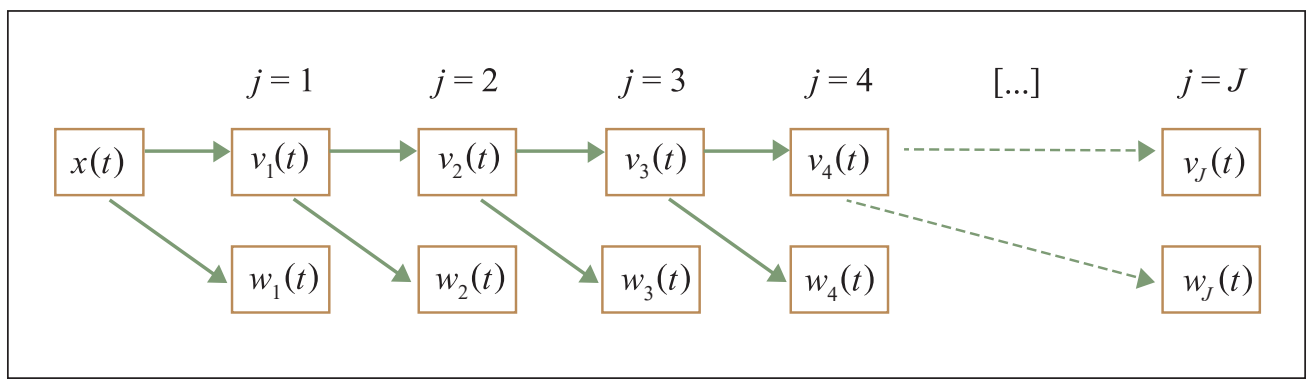

A time series, say $f(t)$, can be decomposed by the wavelet transformation, which can be expressed as follows.

$$
f(t)=\sum_{k} s_{J, k} \phi_{J, k}(t)+\sum_{k} d_{J, k} \psi_{J, k}(t)+\sum_{k} d_{J-1, k} \psi_{J-1, k}(t)+\ldots \ldots .+\sum_{k} d_{1, k} \psi_{1, k}(t)
$$


where $J$ is the number of multi-resolution levels, and k ranges from 1 to the number of coefficients in each level. The wavelet coefficients $s_{J, K}, d_{J, K}, \cdots d_{1, k}$ are the wavelet transform coefficients, and $\phi_{J, K}(t)$ and $\psi_{j, k}(t)$ represent the approximating wavelets functions. The wavelets transformations can be expressed as

$$
\begin{gathered}
s_{J, k}=\int \phi_{J, k}(t) f(t) d t \\
d_{j, k}=\int \psi_{j, k}(t) f(t) d t, \text { for } j=1,2, \ldots \ldots . . J .
\end{gathered}
$$

where $J$ is the maximum integer such that $2^{J}$ takes a value less than the number of observations.

The detail coefficients, $d_{J, K}, \ldots . ., d_{1, k}$, represent increasingly finer scale deviation from the smooth trend and $s_{J, K}$ which represents the smooth coefficient captures the trend. Hence, the wavelet series approximation of the original series $f(t)$ can be expressed follows:

$$
f(t)=S_{J, k}(t)+D_{J, k}(t)+D_{J-1, k}(t)+\ldots . .+D_{1}(t)
$$

Where $s_{J, K}$ is the smooth signal and $D_{J, K}, D_{J-1, k}, D_{J-2, k} \ldots D_{1, k}$ detailed signals. These smooth and detailed signals are expressed as follows:

$$
S_{J, k}=\sum_{k} S_{J, k} \phi_{J, k}(t), D_{J, k}=\sum_{k} d_{J, k} \psi_{J, k}(t), \text { and } D_{1, k}=\sum_{k} d_{1, k} \psi_{1, k}(t), j=1,2, \ldots ., J-1
$$

The $s_{J, K}, D_{J, k}, D_{J-1, k}, D_{J-2, k} \ldots D_{1, k}$ are listed in increasing order of the finer scale components.

\section{Wavelet Correlation}

The estimation of wavelet correlation involves the construction of variances and covariances $\left\{x_{t}\right\}$ and $\left\{y_{t}\right\}$ at different wavelet scales. Wavelet variance essentially refers 
to the substitution of variability over certain scales for the global measure of variability estimated by sample variance. The wavelet variance of stochastic process $X$ is estimated using the MODWT coefficients for scale $\tau_{j}=2^{j-1}$ through:

$$
\hat{\sigma}_{x}^{2}\left(\tau_{j}\right)=\frac{1}{\hat{N}_{j}} \sum_{k=L_{j}-1}^{N-1}\left(\hat{W}_{j, k}\right)^{2}
$$

where $\hat{W}_{j, k}$ the MODWT wavelet coefficient of variable $X$ at scale is $\tau_{j} . \hat{N}_{j}=N=L_{j}+1$ is the number of coefficients unaffected by the boundary, and $L_{j}=\left(2^{j}-1\right)(L-1)$ is the length of the scale $\tau_{j}$ wavelet filter.

Wavelet covariance decomposes the covariance between two stochastic processes on a scale-by-scale basis. The wavelet covariance at scale $\tau_{j}$ can be written as follows:

$$
\gamma_{X Y}\left(\tau_{J}\right)=\operatorname{cov}_{X Y}\left(\tau_{J}\right)=\frac{1}{\hat{N}_{j}} \sum_{k=L_{j}-1}^{N-1} \hat{W}_{j, k}^{x} \hat{W}_{j, k}^{y}
$$

Given the wavelet covariance for $\left\{x_{t}, y_{t}\right\}$ and wavelet variances for $\left\{x_{t}\right\}$ and $\left\{y_{t}\right\}$, the MODWT estimator of wavelet correlation can be expressed as follows:

$$
\hat{\rho}_{x y}\left(\tau_{j}\right)=\frac{\operatorname{Cov}_{x y}\left(\tau_{j}\right)}{\hat{\sigma}_{x}^{2}\left(\tau_{j}\right) \hat{\sigma}_{y}^{2}\left(\tau_{j}\right)}
$$

\section{Wavelet Cross Covariance}

Cross correlation is a powerful tool for examining the relationship between two time series. The cross correlation function considers the two series at lag 0 not only simultaneously but also with a time shift. The cross correlation reveals causal relationships and information flow structures in the sense of Granger causality. If two time series were generated on the basis of a synchronous information flow, they would have a symmetric lagged correlation function, $\rho_{\tau}=\rho-\tau$ the symmetry would be violated only by insignificantly small, purely stochastic deviations. As soon as the deviations 
between $\rho_{\tau}$ and $\rho-\tau$ become significant, there is asymmetry in the information flow and a causal relationship that requires an explanation. The cross correlation can be constructed utilizing the wavelet cross covariance. It is straightforward to derive the cross covariance, once the wavelet covariance is derived. For $\mathrm{N} \geq L_{j}$ a biased estimator of the wavelet cross covariance based on the MODWT is given by

$$
\begin{aligned}
& R_{X Y, \tau}=\left\{1 / \tilde{N} \sum_{T=L j-1}^{N-\tau-1} \tilde{d}_{j, t}^{X} \tilde{d}_{j, t+\tau}^{Y} \quad \text { for } \tau=0, \ldots, \tilde{N}_{J}-1\right. \\
& \left\{1 / \tilde{N} \sum_{T=L j-1}^{N-\tau-1} \tilde{d}_{j, t}^{X} \tilde{d}_{j, t+\tau}^{Y} \quad \text { for } \tau=-1, \ldots,-\left(\tilde{N}_{J}-1\right)\right. \\
& \{0 \quad \text { otherwise }
\end{aligned}
$$

Allowing the two processes to differ by an integer lag $\tau$, the wavelet cross correlation can be defined as

$$
\hat{\rho}_{x, k}\left(\tau_{j}\right)=\frac{\gamma_{x, k}\left(\tau_{j}\right)}{\hat{\sigma}_{1}\left(\tau_{j}\right) \hat{\sigma}_{2}^{2}\left(\tau_{j}\right)}
$$

The wavelet cross-correlation decomposes the cross-correlation between two time series on a scale-by-scale basis. Thus it becomes possible to see how the association between two time series changes with time horizons. Genaçay et al. (2002) define the wavelet cross-correlation as:

$$
\hat{\rho}_{x, k}\left(\tau_{j}\right)=\frac{\gamma_{x, k}\left(\tau_{j}\right)}{\hat{\sigma}_{1}\left(\tau_{j}\right) \hat{\sigma}_{2}^{2}\left(\tau_{j}\right)}
$$

where $\sigma_{x, k}^{2}\left(\tau_{j}\right), \sigma^{2}\left(\tau_{j}\right)$ is respectively the wavelet variances for $x_{1, t}$ and $x_{2, t}$ associated with scale $\tau_{j}$ and $\gamma_{x, k}\left(\tau_{j}\right)$, and the wavelet covariance between $x_{1, t}$ and $x_{2, t-k}$ associated with scale $\tau_{j}$. The usual cross-correlation is used to determine lead-lag relationships between two time series; the wavelet cross-correlation gives a lead-lag relationship on a scale-by-scale basis. 


\section{Discussion}

Our data set consists of weekly stock indices of 14 Asia Pacific markets including the Indian capital market between January 1, 1992 and June 30, 2013. The representative market indices of each country were retrieved from the Bloomberg data base. In order to check the stationarity of the underlying variables, Augmented Dickey Fuller and PhillipPheron tests were carried out followed by basic descriptive statistics ${ }^{2}$. Each return series was found to be stationary at first difference. To assess the distributional properties of return series of sample markets, we begin with descriptive statistics. The weekly average return is found to be positive and ranges between $0.001 \%$ and $0.003 \%$. However, a high level of standard deviation was observed ranging from 0.030 for Japan to 0.040 for South Korea during the sample period. Furthermore, except Malaysia, Taiwan, and Thailand, all other stock returns are negatively skewed meaning that huge negative stock returns are more obvious than huge positive returns. While Kurtosis statistics illustrated that all return series are leptokurtic with a large positive kurtosis value. The Jarque-Bera statistics on the other hand, strongly disapproves the null hypothesis that the Gaussian distribution of returns is normal.

After deconstructing all return series in time frequency localization using MODWT, we proceed with wavelet multiple correlation (Fernandez 2012) ${ }^{3}$.

\footnotetext{
${ }^{2}$ For the sake of brevity, results of unit root test and descriptive statistics are not reported.

${ }^{3}$ For wavelet multiple correlations we rely on simulation exercises carried out by Javier Fernandez (2012).
} 
Figure 2. Wavelet multiple correlations between Asia Pacific equity markets

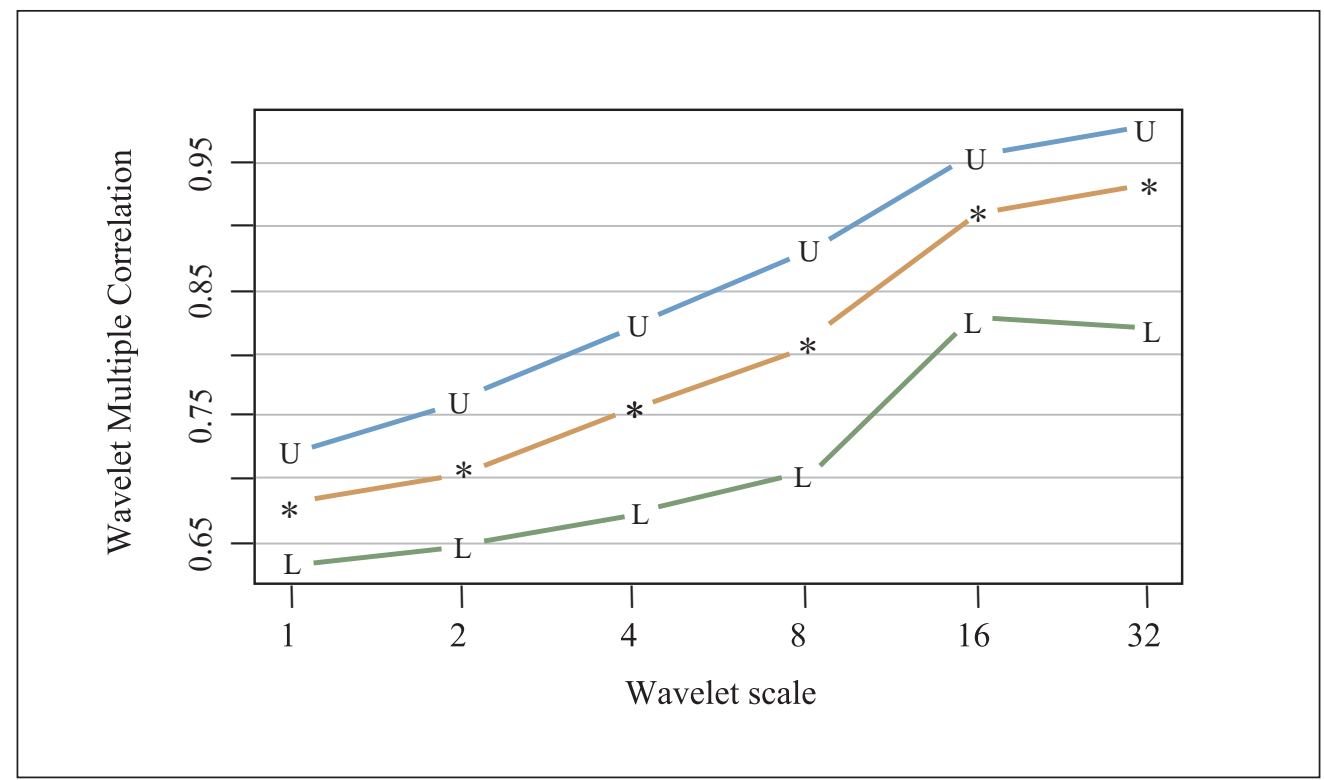

(Note) U \& L corresponds to upper and lower bounds of the $95 \%$ confidence interval.

Figure 2 demonstrates that Asia Pacific markets are correlated on each scale but the correlation grows stronger with lower frequencies of data. Overall the plot shows that correlation between Asia Pacific markets ranges from 0.65 in the 4 weeks period to 0.95 in the 128 weeks period. However, the information derived from wavelet multiple correlations could be helpful for institutional investors who target particular regions mostly for their investment outlet rather than individual investors who keep a micro eye on particular markets. Hence to address this serious methodological concern, we make use of wavelet correlation and cross correlation. Given the sample of 1124 observations or roughly 22 years of data, the maximum decomposition possibility is given by $[\log 2(T)]$. However, for higher level decompositions, there is significant possibility that feasible wavelet coefficients become smaller and boundary conditions are violated. A boundary is simply a character string indicating the boundary method used in the decomposition by assuming it to be either periodic or a reflection. According to Gencay et al. (2002), the most natural technique for dealing with a boundary is to assume the length $N$ series as periodic and grab observations from the other end to finish the computations. Thus based on the periodic assumption, we choose to restrict the decomposition of time series of stock returns into six details (Wi1 to Wi6) and one (Vi6) smooth component. The 
wavelet scales are such that scale 1 is associated with the 2-4 week period (intra monthly scale), scale 2 with the 4-8 week period (two month scale), scale 3 with the 8-16 week period (quarterly scale), scale 4 with the 16-32 week period (bi-annual scale), scale 5 with the 32-64 weeks period (yearly scale), scale 6 with the 64-128 week period (Two year scale), and the last scale represents smooth decomposition. Overall we generated 84 return series from 14 original raw return series $(14 * 6)$ without losing any data points or informational content. For several reasons, we do not report the results for the smooth series since it captures a long term fluctuation where the predetermined frequency component is not known. Table 1 presents both Pearson as well as wavelet correlation coefficients between India and Asia Pacific markets with upper and lower bounds of $95 \%$ confidence intervals.

Table 1. Wavelet correlations between Indian and Asia Pacific equity markets

\begin{tabular}{|l|c|c|c|c|c|c|c|c|}
\hline Countries & P. Correlation & D1 & D2 & D3 & D4 & D5 & D6 & Mean \\
\hline Bangladesh & $\mathbf{- 0 . 0 2}$ & $-0.04 *$ & $0.04 *$ & $0.02 *$ & $-0.02 *$ & -0.15 & $-0.02 *$ & $\mathbf{0 . 0 9}$ \\
\hline China & $\mathbf{0 . 2 4}$ & 0.16 & 0.22 & 0.26 & 0.35 & 0.44 & 0.51 & $\mathbf{0 . 3 5}$ \\
\hline Hong Kong & $\mathbf{0 . 3 2}$ & 0.28 & 0.31 & 0.33 & 0.48 & 0.60 & 0.68 & $\mathbf{0 . 4 5}$ \\
\hline Indonesia & $\mathbf{0 . 2 7}$ & 0.23 & 0.25 & 0.28 & 0.32 & 0.60 & 0.70 & $\mathbf{0 . 4 0}$ \\
\hline Japan & $\mathbf{0 . 2 8}$ & 0.25 & 0.30 & 0.34 & 0.38 & 0.37 & 0.55 & $\mathbf{0 . 3 7}$ \\
\hline Korea & $\mathbf{0 . 3 1}$ & 0.29 & 0.30 & 0.29 & 0.32 & 0.53 & 0.59 & $\mathbf{0 . 3 9}$ \\
\hline Malaysia & $\mathbf{0 . 2 0}$ & 0.15 & 0.20 & 0.25 & 0.28 & 0.50 & 0.61 & $\mathbf{0 . 3 3}$ \\
\hline Pakistan & $\mathbf{0 . 1 1}$ & $-0.02 *$ & 0.10 & 0.27 & 0.22 & 0.37 & 0.62 & $\mathbf{0 . 2 6}$ \\
\hline Philippines & $\mathbf{0 . 2 5}$ & 0.17 & 0.21 & 0.28 & 0.40 & 0.65 & 0.71 & $\mathbf{0 . 4 0}$ \\
\hline Singapore & $\mathbf{0 . 2 4}$ & 0.21 & 0.29 & 0.33 & 0.45 & 0.52 & 0.61 & $\mathbf{0 . 4 0}$ \\
\hline Taiwan & $\mathbf{0 . 2 4}$ & 0.15 & 0.28 & 0.30 & 0.35 & 0.53 & 0.58 & $\mathbf{0 . 3 7}$ \\
\hline Thailand & $\mathbf{0 . 2 6}$ & 0.20 & 0.25 & 0.32 & 0.34 & 0.55 & 0.57 & $\mathbf{0 . 3 7}$ \\
\hline Mean & $\mathbf{0 . 1 1}$ & $\mathbf{0 . 2 0}$ & $\mathbf{0 . 2 4}$ & $\mathbf{0 . 2 9}$ & $\mathbf{0 . 3 5}$ & $\mathbf{0 . 4 5}$ & $\mathbf{0 . 6 1}$ & $\mathbf{- 1}$ \\
\hline
\end{tabular}

(Notes) (i) Asterisk coefficient denotes insignificant correlation against zero correlation. All remaining coefficients are statistically significant at $1 \%$ level.

(ii) D1:2-4 week period, D2 : 4-8 week period, D3 : 8-16 week period D4 : 16-32 week period D5 : 32-64 week period D6 : 64-128 week period. 
The Pearson Correlation on average demonstrates $11 \%$ correlation between the Indian equity market and the rest of the Asia Pacific equity markets. However, the wavelet correlation reveals that this particular degree of relationship could be realistic for shorter intervals only. In other words, it infers that lower frequency domains are essentially associated with strong linkages among markets which require attention of investors, fund managers, and policy makers. The average wavelet correlation of Indian equity market with those of sample markets comprise comprise 0.20 for D1, 0.24 for D2, 0.29 for D3, 0.35 for D4, 0.45 for D5, and 0.61 for D6. In other words the integration of the Indian equity market with rest of the Asia Pacific markets ranges from $20 \%$ during the 4 week's period to $61 \%$ during the 128 week's period. This implies that the investors with short term investment horizons can enjoy international portfolio diversification and also asset allocations. While portfolio diversification would help them in reducing business risk, asset allocation would facilitate stabilization of returns particularly over extended periods when markets are relatively integrated. The results also suggest that higher frequencies, shorter intervals, are attractive for risk-averse investors. However as the investment interval is increased from four weeks (D1) to eight weeks (D2) to sixteen weeks (D3) and so on, diversification opportunities are monotonically reduced. These findings infer that investors as well as fund managers must rebalance their portfolios with respect to different asset classes. The strong correlations over lower frequency intervals imply that Indian investors will seek less information asymmetry by demanding better governance, larger quantity, and superior information disclosure through security regulations and financial reports. This will in turn lead to a reduction of the cost of capital. However, such integration could also affect their expected returns or cost of capital. For example; volatilities of stock market returns of developing markets like India are generally higher than those of developed markets like Japan and Korea. As a result, to keep the variance and covariance constant, the prices of a market index should increase and expected returns should decrease. When the Indian market becomes more integrated with say, Japan and South Korea, the sensitivity of its market return increases and so does the covariances of its market with Japan and South Korea. When the increase in covariance is smaller than the increase in local stock variances, the prices are typically higher. Errunza and Miller (2000) describes the cost of capital or expected return of any security in the integrated market to be lower because trades on segmented markets are mostly carried out by local investors and their expected return depends on the local price risk and national covariance risk.

Next we proceed with the wavelet cross correlation function as a measure of the 
similarity of two waveforms and a function of a time-lag applied to one of them. It is obtained by allowing 15 lags between observed and fitted values from the same linear combination at each of the wavelet scales. In particular, we studied whether there exists any pulling effect between the Indian equity market and the rest of the Asia Pacific markets i.e., whether at a given time the return value of one market such as Japan influences that of another market like India at contrasting time lags. Table 2 summarizes the cross wavelet coefficients between Indian and Asia Pacific markets.

Table 2. Wavelet cross correlation between Indian and Asia Pacific equity markets

\begin{tabular}{|l|c|c|c|c|c|c|c|c|c|c|c|c|c|c|}
\hline & \multicolumn{1}{|c|}{ Lagged correlation at Level 3 } & \multicolumn{1}{c|}{ Lagged correlation at Level 4 } \\
\hline Country & $\mathbf{- 1 5}$ & $\mathbf{- 1 0}$ & $\mathbf{- 5}$ & $\mathbf{0}$ & $\mathbf{5}$ & $\mathbf{1 0}$ & $\mathbf{1 5}$ & $\mathbf{- 1 5}$ & $\mathbf{- 1 0}$ & $\mathbf{- 5}$ & $\mathbf{0}$ & $\mathbf{5}$ & $\mathbf{1 0}$ & $\mathbf{1 5}$ \\
\hline Bangladesh & 0 & 0 & 0 & 0.00 & 0 & 0 & 0 & 0 & 0.00 & -0.1 & 0.00 & -0.1 & 0.00 & 0 \\
\hline China & 0 & 0 & 0 & 0.26 & 0 & 0 & 0 & 0 & -0.30 & 0 & 0.35 & 0 & 0.20 & 0 \\
\hline Hong Kong & 0 & 0 & 0 & 0.33 & 0 & 0 & 0 & 0 & -0.25 & 0 & 0.48 & 0 & 0.20 & 0 \\
\hline Indonesia & 0 & 0 & 0 & 0.28 & 0 & 0 & 0 & 0 & -0.25 & 0 & 0.32 & 0 & 0.00 & 0 \\
\hline Japan & 0 & 0 & 0 & 0.34 & 0 & 0 & 0 & 0 & -0.20 & 0 & 0.38 & 0 & -0.25 & 0 \\
\hline Korea & 0 & 0 & 0 & 0.29 & 0 & 0 & 0 & 0 & -0.30 & 0 & 0.32 & 0 & 0.25 & 0 \\
\hline Malaysia & 0 & 0 & 0 & 0.25 & 0 & 0 & 0 & 0 & -0.35 & 0 & 0.28 & 0 & 0.00 & 0 \\
\hline Pakistan & 0 & 0 & -0.1 & 0.27 & -0.1 & 0 & 0 & 0 & -0.10 & 0 & 0.22 & 0 & 0.00 & 0 \\
\hline Philippines & 0 & 0 & 0 & 0.28 & 0 & 0 & 0 & 0 & -0.10 & 0 & 0.40 & 0 & -0.10 & 0 \\
\hline Singapore & 0 & 0 & 0 & 0.33 & 0 & 0 & 0 & 0 & -0.25 & 0 & 0.45 & 0 & 0.25 & 0 \\
\hline Taiwan & 0 & 0 & 0 & 0.30 & 0 & 0 & 0 & 0 & -0.20 & 0 & 0.35 & 0 & -0.20 & 0 \\
\hline Thailand & 0 & 0 & 0 & 0.32 & 0 & 0 & 0 & 0 & -0.20 & 0 & 0.34 & 0 & 0.00 & 0 \\
\hline
\end{tabular}




\begin{tabular}{|l|c|c|c|c|c|c|c|c|c|c|c|c|c|c|}
\hline & \multicolumn{4}{|c|}{ Lagged correlation at Level 5 } & \multicolumn{3}{c|}{ Lagged correlation at Level $\mathbf{6}$} \\
\hline Country & $\mathbf{- 1 5}$ & $\mathbf{- 1 0}$ & $\mathbf{- 5}$ & $\mathbf{0}$ & $\mathbf{5}$ & $\mathbf{1 0}$ & $\mathbf{1 5}$ & $\mathbf{- 1 5}$ & $\mathbf{- 1 0}$ & $\mathbf{- 5}$ & $\mathbf{0}$ & $\mathbf{5}$ & $\mathbf{1 0}$ & $\mathbf{1 5}$ \\
\hline Bangladesh & 0.00 & -0.1 & -0.15 & -0.15 & -0.10 & 0 & 0.0 & 0.0 & 0.0 & 0.0 & 0.0 & 0.0 & 0.0 & 0.0 \\
\hline China & -0.20 & -0.1 & 0.30 & 0.44 & 0.35 & 0.3 & -0.2 & 0.30 & 0.35 & 0.40 & 0.51 & 0.55 & 0.5 & 0.3 \\
\hline Hong Kong & -0.25 & -0.1 & 0.20 & 0.60 & 0.50 & 0.3 & -0.1 & 0.25 & 0.40 & 0.50 & 0.68 & 0.50 & 0.4 & 0.35 \\
\hline Indonesia & -0.20 & 0.0 & 0.25 & 0.60 & 0.40 & 0.1 & -0.2 & 0.00 & 0.30 & 0.40 & 0.70 & 0.60 & 0.5 & 0.50 \\
\hline Japan & 0.00 & 0.1 & 0.25 & 0.37 & 0.25 & 0.0 & 0.0 & 0.50 & 0.55 & 0.60 & 0.55 & 0.50 & 0.3 & 0.10 \\
\hline Korea & -0.25 & 0.0 & 0.25 & 0.53 & 0.40 & 0.2 & -0.1 & 0.25 & 0.40 & 0.50 & 0.59 & 0.60 & 0.5 & 0.45 \\
\hline Malaysia & -0.10 & 0.0 & 0.40 & 0.50 & 0.50 & 0.0 & -0.1 & 0.00 & 0.45 & 0.55 & 0.61 & 0.55 & 0.5 & 0.40 \\
\hline Pakistan & -0.25 & -0.1 & 0.10 & 0.37 & 0.40 & 0.2 & 0.0 & 0.00 & 0.25 & 0.50 & 0.62 & 0.65 & 0.6 & 0.50 \\
\hline Philippines & -0.40 & 0.0 & 0.40 & 0.65 & 0.40 & 0.2 & -0.2 & 0.00 & 0.20 & 0.45 & 0.71 & 0.55 & 0.5 & 0.45 \\
\hline Singapore & -0.30 & 0.0 & 0.35 & 0.52 & 0.40 & 0.2 & -0.1 & 0.00 & 0.30 & 0.40 & 0.61 & 0.60 & 0.5 & 0.40 \\
\hline Taiwan & -0.10 & 0.0 & 0.25 & 0.53 & 0.25 & 0.0 & -0.2 & 0.50 & 0.60 & 0.65 & 0.58 & 0.50 & 0.4 & 0.20 \\
\hline Thailand & -0.35 & -0.2 & 0.20 & 0.55 & 0.50 & 0.3 & 0.0 & 0.20 & 0.45 & 0.60 & 0.57 & 0.57 & 0.5 & 0.40 \\
\hline
\end{tabular}

(Note) Level 3, Level 4, Level 5 and Level 6 denotes wavelet decomposition scales capturing market return fluctuations over 16, 32,64 and 128 weeks respectively for sample countries. Coefficients other than those of zeros are statistically significant at $1 \%$ against zero correlation.

We have not reported coefficients for Level 1 which is associated with the 4 weeks period and Level 2 which is associated with the 8 weeks period as they were all zeros, which means that there exist no lead lag effects between Indian and Asia Pacific equity markets during higher frequencies or shorter intervals. The coefficients also remained zeros in wavelet scale 3 which is associated with the 16 weeks period. However when the wavelet scale was increased to level 4 which is associated with the 32 weeks period, the lead lag effect between Indian and sample markets become evident at lag $(-10$ \& +10 ). The interesting thing to be observed is that from the prior ten weeks $(-10)$ to lag 0 , the Indian market is negatively correlated with the underlying markets but the interaction turned out to be positive for most of the markets except for Taiwan, the Philippines, and Japan during the next ten weeks $(+10)$. The coefficients at level 5 which is associated with the 64 weeks period exhibit a negative lead lag effect during prior $(-15)$ weeks and also during subsequent (15) weeks following the original lag. The positive cross correlation is detected during the $(-5$ to +5$)$ time lag. Finally some unique results are 
observed at level 6, capturing stock return fluctuations for the 128 weeks period. During this period, the Indian market is positively and extensively correlated at all studied lags. Figure 3 shows the cross correlation plot between Indian and Japanese equity returns. 
Figure 3. Wavelet cross correlation between stock returns of India and Japan

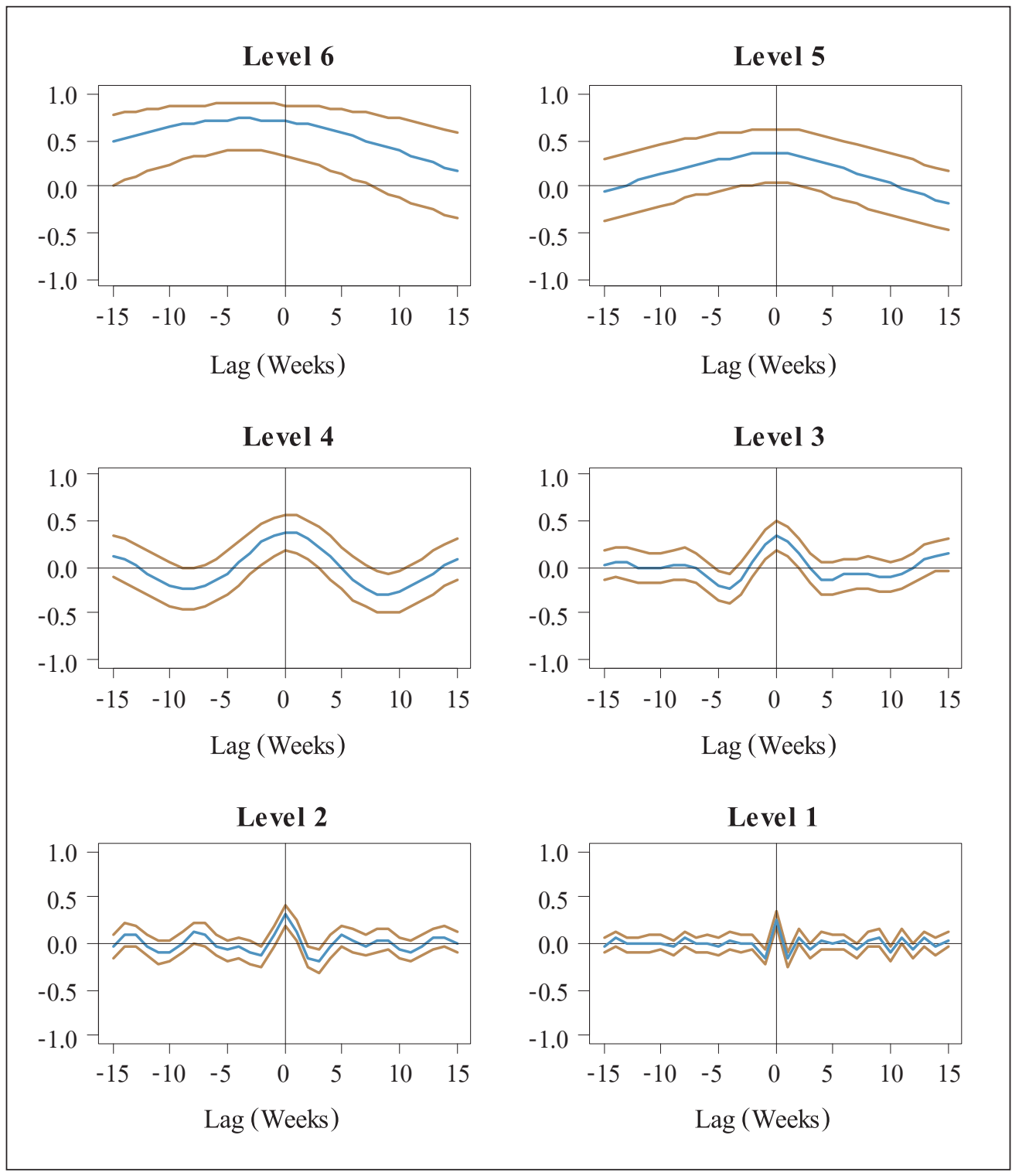

(Note) The cross-correlation is calculated using daubechies Least Asymmetric (LA) wavelet filter of length by shifting the second index in the pair (in this case Japan). The $95 \%$ confidence intervals are drawn with a dotted line. The red lines denote upper and lower bounds of the $95 \%$ confidence interval. The black line shows the cross correlation at different lags. Level 1=2-4 weeks, Level 2=4-8 weeks, Level 3=8-16 weeks, Level 4= 1632 weeks, Level 5=32-64 weeks and Level 6=64-128 weeks. 
The existence of a lead lag relationship is clearly apparent at lower frequencies or longer intervals but not at higher frequencies or shorter intervals. This implies that a price change in the Indian market appears later in time than changes in the Japanese market. Hence, it is inferred that the Japanese market is able to pull the Indian market in the lower frequency scales. Similar findings with more or less deviation are apparent with other markets. Therefore we argue that unexpected changes in Asia Pacific markets could provide a clue to Indian investors holding investment approximately up to 3 years regarding the effect of that change on the Indian equity market so that they have enough time to manage and rebalance their investment portfolios. We reported only one cross correlation between stock returns of India and Japan to help readers understand how plotting estimation was carried out.

\section{Conclusion}

This paper used maximal overlap discrete transform analysis estimator for visualizing the characteristics of international market returns in simultaneous time-frequency scales to provide additional insights in dynamic linkages of Indian stock market with those of Asia Pacific markets and we believe that the analysis can contribute to the risk diversification process both for Indian as well as investors from sample countries. In particular the study tried to establish the wavelet method as a new analytic technique to examine the scope of risk and portfolio diversification given the diverse investment horizons. Our results, based on wavelet multiple correlations, indicate two aspects of integration among Asia Pacific markets. First, they are highly integrated at all studied frequencies. Second, the integration grows stronger with lower frequencies or longer intervals. The wavelet correlation further reveals that as the investment interval is increased from two weeks to four weeks to eight weeks and so on, the diversification opportunities are progressively reduced. However same is not true with Bangladeshi equity market which is found to be weakly and negatively correlated with Indian market at all frequencies. This in turn implies the possibility of portfolio diversification for short, medium as well as long terms investors operating in Indian market. Overall the monotonic increase in correlations between Indian and sample markets implies few things. It could produce a number of efficiency gains which can accrue directly and 
indirectly to the participants of the Indian stock exchange like intermediaries (brokers), final investors and issuers. For example; participants in stock markets generally face two types of costs i,e., implicit and explicit cost. The stock market integration at longer intervals can reduce both implicit and explicit cost of trading (Pagano 2005). Also, due to growing integration, domestic Indian firms have to compete directly with foreign rivals and this competition according to Kose et al., (2006) could lead to better corporate governance. The results of cross correlation suggest that Indian investors can make projections on their own market from the sudden changes in other Asian markets at lower frequencies. However the investment of market participants could be more vulnerable to economic crises at lower frequencies. The possible reasons may be the contagion effect ${ }^{4}$ as discussed by Roll (1988) and King and Wadhwani (1990). Such findings are largely absent from previous empirical research on diversification and dependence in international markets. Thus an important implication of our findings suggest that the degree of Indian market integration with those of Asian markets tends to change over time and because of the time-varying nature of correlations, benefits of diversification are also time-varying. Overall the results are plausible for Indian investors and fund managers because not only it provides an insight to Indian investors as when to increase/decrease participation in any specific Asia pacific market but also provides the information to foreign Investors regarding the appropriate time and duration to participate in Indian market. The findings suggest that the investors can mitigate the risk element involved in the international investment and maximize the returns on higher (shorter) frequency intervals. Adaptation of simultaneous time frequency analysis in present study although has facilitated comprehensive analysis of Indian stock market integration but the study leave huge scope for examining linkages among bond, derivative and commodity markets of India and across Asia Pacific regions.

Received 16 April 2014, Revised 1 October 2015, Accepted 5 January 2016

\footnotetext{
${ }^{4}$ Contagion can be described as a situation where an economic or financial shock in a particular economy or region spread across other countries. For detailed discussion on contagion effect, Moser (2003) may be referred.
} 


\section{References}

Ang and Bekaert, G. "International Asset Allocation with Regime Shifts." Review of Financial Studies 15, no.4 (2002): 1137-1187.

Bekaert and Harvey C. "Time- Varying World Market Integration." Journal of Finance 5, no. 2 (1995): 403-444.

Bose and Mukharjee P. "A Study of Inter-linkages between the Indian Stock Market and Some other Emerging and Developed Markets." (2006): 9th Capital Markets Conference Paper, Mumbai.

Brooks and Negro, D. "The rise in co-movement across national stock markets: market integration or IT bubble.” Journal of Empirical Finance, 11, no.5 (2004): 659-680.

Chung, P. and D. Liu. "Common Stochastic Trends in Pacific Rim Stock Markets." Quarterly Review of Economics and Finance 34, no. 3 (1994): 241-259.

Deo and Shah A. "Scaling Properties of Systematic Risk: A New Evidence from Wavelet Analysis." Asia-Pacific Journal of Management Research and Innovation 8, no.3 (2012a): 283-289.

"Wavelet Based Beta Estimation: Applications to Indian Stock Market." Kuwait Chapter of Arabian Journal of Business and Management Review 1, no.11 (2012b): 96-10.

Errunza and Miller D. "Market Segmentation and the Cost of Capital in International Equity Markets.” Journal of Financial and Quantitative Analysis 35, no 4 (2000): 577600.

Fernandez, M. "Wavelet Multiple Correlation and Cross-correlation: A Multi-Scale Analysis of Euro-zone Stock Markets.” phycica A 391, no.4 (2012): 1097-1104.

Fernandez, V. "Decomposition of Stock Returns Spillovers and Detection of Breakpoints in Volatility. Centre for Applied Economics." Department of Industrial Engineering, University of Chile, Santiago (2005)

Forbes and Rigobon R. "No Contagion, Only Interdependence: Measuring Stock Market Comovements." Journal of Finance 57, no.2 (2002): 2223-2261.

Gencay, Selcuk and Whitcher, B. An Introduction to Wavelets and Other Filtering Methods in Finance and Economics. (New York: Academic Press 2002) 
Goetzmann, Li, and Rouwenhorst, K. "Long-term Global Market Correlations." Journal of Business. 78, no 1. (2005): 1-38.

Granger and Morgenstern, O. The Predictability of Stock Market Prices. (Lexington: Heath Lexington Book 1970)

Grubel, H. "Internationally Diversified Portfolios: Welfare Gains and Capital Flows." American Economic Review 58, no. 5 (1968): 1299-1314.

Hassler, J. "Regime Shifts and Volatility Spillovers on International Stock Markets." (1995): IIES Seminar Paper, 603.

Islam, R. "A Comparison of the Long Term Interdependence of Southeast Asian Equity Markets.” Journal of East Asian Economic Integration 18, no.2, (2014): 187-212.

Kasa, K. "Common Stochastic Trends in International Stock Markets." Journal of Monetary Economics 29, no.1 (1992): 95-124.

Khaled, Ftiti and Ilyes A. "Greece Stock Market Integration with Southeast Europe." Journal of economic Integration 28, no.4 (2013): pp. 668-682

Kose, Prasad, Kenneth, and Wei, S. "Financial Globalization: A Reappraisal." IMF Working Paper, (2006): wp/06/189.

King and Wadhwanil S. "Tramsmissian of Volatility between Stack Markets." Review of Financial studies 3, no. 1 (1990): 5-33.

Lee, H. "International Transmission of Stock Market Movements: A Wavelet Analysis." Applied Economics Letters 11, no. 3 (2004): 197-201.

Levy and Sarnat, M. "International Diversification of Investment Portfolios." American Economic Review 60, no. 4 (1970): 668-675.

Longin and Solnik, B. "Extreme Correlation of International Equity Markets." Journal of Finance 56, no. 2 (2001): 649-675.

Markowitz, H. “Portfolio Selection.” Journal of Finance 7, no. 1 (1952): 77-91.

Moser, T. "What is international financial contagion?" International Finance 6, no. 2 (2003): 157-78.

Mukherjee, D. "Comparative Analysis of Indian Stock Market with International Markets." Great Lakes Herald 1, no. 1 (2007): 39-71. 
Parul and Gupta, P. Economic Environment and Policies for Business. (New Delhi: Tata McGraw Hill Education, 2012)

Percival and Walden, A. Wavelet Methods for Time Series Analysis. (Cambridge: Cambridge Press 2000)

Raghavan, Dark and Maharaj, E. "Impact of Capital Control Measures on the Malaysian Stock Market: A Multi-resolution Analysis.” International Journal of Managerial Finance 6, no. 2 (2010): 116-127.

Raj and Dhal, S. "Integration of India's Stock Market with Global and Major Regional Markets." Regional Financial Integration in Asia: Present and Future, no. 42. (2008): BIS papers.

Ramsey and Lampart, C. "Decomposition of Economic Relationships by Timescale Using Wavelets.” Macroeconomic Dynamics 2, no. 1 (1998a): 49-71.

"The Decomposition of Economic Relationships by Time Scale Using Wavelets: Expenditure and Income." Studies in Nonlinear Dynamics and Econometrics 3, no.1 (1998b): 23-42.

Richards, A. "Co-movements in National Stock Market Returns: Evidence of Predictability, but not Co-integration." Journal of Monetary Economics, 36, no.3 (1995): 631-654.

Roll, R. “The International Crash of October 1987.” Financial Analysts Journal 44, no.5 (1988): 19-35.

Rua and Nunes, L. "International Co-movement of Stock Market Returns: A Wavelet Analysis." Journal of Empirical Finance 16, no 4 (2009): 632-639.

Shiller, R. "Co-movements of Stock Prices and Co-movements in Dividends" Journal of Finance 44, no. 3 (1989): 719-729.

Syriopoulos, T. "Dynamic Linkages between Emerging European and Developed Stock Markets: Has the EMU any Impact?" International Review of Financial Analysis 16, no. 1 (2007): 41-60.

Tripathi and Sethi, S. "Integration of Indian Stock Market with Major Global Stock Markets." Asian Journal of Business and Accounting 3, no. 1 (2010): 117-134.

Voronkova, S. "Equity Market Integration in Central European Stock Markets: A Co- 
integration Analysis with Shifting Regime." International Review of Financial Analysis 13, no.5 (2004): 633-647. 